The urinary oxygen tension is dependent upon an equilibrium between the urine oxygen and the oxygen tension in the tubules of the medulla and has been shown to respond to changes in renal blood flow. ${ }^{27}$ Conflicting effects of mannitol on urine oxygen tension have been reported. ${ }^{28-30}$ Our data revealed no real influence of mannitol on urinary oxygen tension and no difference between the oxygen tension of the transplant and the normal side. As the renal blood flow of the transplant is much less than in the normal kidney, it is conceivable that there is a preferential reactive hyperemia in the medullary area of the transplant that is responsible for this lack of difference in the oxygen tension between the two kidneys. In support of this is the supranormal oxygen tension after severe constriction of the renal artery noted by Martin. ${ }^{27}$

\section{Summary}

In a recently autotransplanted kidney, $20 \%$ mannitol is more effective than $20 \%$ urea, $6.7 \%$ urea, or saline in raising renal blood flow, raising flow through other systemic arteries, increasing the urine output and decreasing the hematocrit value.

Observed increases in glomerular filtration rate and sodium reabsorption after mannitol and urea are probably more a reflection of increased urine output than of a true rise in these parameters.

Urine oxygen tension was not affected by mannitol.

A sustaining solution of mannitol at high doses will maintain an elevated blood flow in both renal and nonrenal vessels.

It is concluded that the transient improvement in renal blood flow with mannitol is primarily a reflection of increased intravascular volume and increased cardiac output. Its clinical usefulness must be guided by an understanding of this mechanism.

This study was aided in part by Public Health postdoctoral fellowship I-F3-HE-19, 359-01.

\section{REFERENCES}

1. Smith, L.; Berman, L.; and Chisholm, G.: Effect of Mannitol on Renal Function During Cardiovascular Surgery, Surg Forum 14:103, 1963.

2. Callaway, J.; Pinkerton, J.; and Foster, J.: Prevention of Acute Renal Failure, Surg Forum 14:101, 1963.

3. Doberneck, R.; Schwartz, F.; and Barry, K.: Comparison of Prophylactic Value of $20 \%$ Mannitol, $4 \%$ Urea, $5 \%$ Dextrose on the Effects of Renal Ischemia, J Urol 89: $300,1963$.

4. Beall, A., et al: Mannitol Diuresis in Vascular Surgery, Arch Surg $86: 34,1963$.

5. Barry, K.G., and Malloy, J.P.: Oliguric Renal Failure, $J A M A$ 179:510, 1962

6. Nosowsky, E., and Kaufman, J.: Protective Action of Mannitol in Renal Artery Occlusion, J Urol 89:295, 1963.

7. Parry, W.; Schaefer, A.; and Mueller, B.: Experimental Studies of Acute Renal Failure, J Urol 89:1, 1963.

8. Lempert, N.; Baba, A.; and Powers, S.: Correction of Oliguric Response to Trauma With $10 \%$ Mannitol, Surg Forum $12: 90,1961$.

9. Peters, G., and Brunner, H.: Mannitol Diuresis in Hemorrhagic Hypotension, Amer J Physiol 204(2):555, 1963.

10. Dempster, W.J.: Reassessment of Anuria After Kidney Transplantation, Brit Med J 1(2):1697, 1963.

11. Starzl, T.: Experience in Renal Transplantation, Philadelphia: W. B. Saunders Co., 1964.

12. Humphries, A., et al: Successful Reimplantation of 12. Humphries, A., et al: Successful Reimplantation of
the Canine Kidney After 24-Hour Storage, Surgery $54: 136$, 1963.

13. Telander, R.: Prolonged Normothermic Perfusion of Isolated Baboon and Sheep Kidney, Surg Forum $13: 378$, 1962.

14. Anderson, M.: Function of Totally Denervated Rabbit Kidney, Scand J Clin Lab Invest $14: 343,1962$.

15. Leary, F.J.; Utz, D.; and Wakim, K.: Effect of Continuous and Intermittent Renal Ischemia on Renal Function, Surg Gynec Obstet 116:311, 1963.

16. Hardin, C., and Valk, W.L.: Effects of Temporary Ischemia on Renal Function Under Normal and Hypothermic Temperatures With Aortic Renal Graft Replacement, Surg Gynec Obstet 106:82, 1958.

17. Bricker, N.S., et al: The Functional Capacity of the Kidney Denervated by Autotransplantation in the Dog, $J$ Clin Invest $37: 185,1958$

18. Doberneck, R.; Schwartz, F.; and Barry, K.: On the Nature of the Nonspecific Nephropathy Attributed to Mannitol, Proc Soc Exp Biol Med 110:795, 1962.

19. Murphy, G.; Gagnon, J.; and Teschan, P.: Renal Hemodynamic Effect of Mannitol in Normotension and Hypotension, Surg Forum 14:99, 1963.

20. Wright, H., and Gann, D.: Effect of Mannitol on Renal Hemodynamics During Extracellular Fluid Volume Depletion and Expansion, Surg Forum 14:97, 1963.

21. Goeller, V., and Schlegel, J.: Observations on Renal Flood Flow and Its Dependence on Fluid Administration, Surg Forum $12: 487,1961$.

22. Winton, F.R.: "Hydrostatic Pressure Affecting the Flow of Urine and Blood in Kidney," Harvey Lectures 1951-52, Academic Press 47, 1953.

23. Murphy, G.; Gagnon, J.; and Teschan, P.: Measurement of Renal Function in Hemorrhagic Hypotension-Effect of Mannitol, J Urol 90(2):133, 1963.

24. Selkurt, E.: Changes in Renal Clearance Following Complete Ischemia of the Kidney, Amer J Physiol 144:395, 1945 .

25. Selkurt, E.: Renal Blood Flow in Clearance of Hemorrhagic Shock, Amer J Physiol 145:696, 1946.

26. Lassen, N.; Munck, O.; and Thaysen, J.H.: Renal Oxygen Consumption, Acta Physiol Scand 51:371, 1961.

27. Martin, D.: Partial Pressure of Oxygen in Urine and 27. Martin, D.: Partial Pressure of Oxygen
Its Significance, Surg Forum 14:496, 1963 .

28. Leonhardt, K., and Landes, R.: Oxygen Tension of Urine and Renal Structures, New Eng J Med 269(3):115, 1963.

29. Hostnik, W., et al: Hemodynamics and Oxygen Ten. sion in Urine and Renal Vein, Surg Forum 10:872, 1959.

30. Aukland, K.: Urine Oxygen Tension, Acta Physiol Scand 55:362, 1962. 


\title{
Blood Coagulation in Uremic Patients Before and After Hemodialysis and Transplantation of the Kidney
}

\author{
K. N. von KAULLA, MD; E. von KAULLA, MD; S. WASANTAPRUCK, MD; \\ T. L. MARCHIORO, MD; AND T. E. STARZL, MD, DENVER
}

\begin{abstract}
A Lthough the bleeding tendency of patients with renal failure is well known, the literature concerning the cause of the coagulation failure is both meager and confusing. The hemostatic abnormality has been said to be greater in acute than in chronic uremia, and even to occur by a different mechanism. ${ }^{21} \mathrm{~A}$ variety of clotting defects have been described in both types of patients. Various plasma clotting factors have been found to be moderately reduced ${ }^{10}$ with inconstant hypofibrinogenemia, ${ }^{8-10}$ with or without involvement of the prothrombin complex. ${ }^{5,9}$ Abnormal thrombelastograms, reduced heparin tolerance, ${ }^{8}$ and prolonged thrombin time ${ }^{10}$ have also been seen in many, but not all, patients.

The most consistently reported coagulation abnormality of uremia has been a deficiency in prothrombin consumption., $4,5,10$, ${ }^{21,22}$ In some cases, this could be explained solely by the thrombocytopenia which has been thought by some to be a common ${ }^{9,21}$ and by others to be a rare $^{6}$ complication of azotemia. In a significant number of patients, however, poor prothrombin consumption and other abnormalities of platelet
\end{abstract}

\footnotetext{
Submitted for publication Oct 19, 1965.

From the departments of medicine and surgery, the University of Colorado School of Medicine and the Veterans Administration Hospital, Denver.

Reprint requests to $4200 \mathrm{E}$ Ninth Ave, Denver, Colo 8022 (Dr. Starzl).
}

function have occurred in the absence of thrombocytopenia. Cahalone et $\mathrm{al}^{4}$ believed that there was inhibition or destruction of platelet factor-3 activity in the uremic plasma of such patients with the consequent loss of platelet thromboplastic function. In a subsequent report the presence of any platelet abnormality was denied. ${ }^{1}$

In previous times, precise knowledge of clotting in the terminally uremic patient was of limited practical use since death was frequently imminent and unpreventable. With the development of renal dialysis and homotransplantation, the outlook is no longer hopeless and the avoidance and control of hemorrhage has assumed increased importance. In this report an attempt will be made to characterize the coagulation abnormalities of uremia, to enumerate the screening tests used for detection of potential bleeders, to evaluate the methods available for correction of the clotting defects, and to describe some effects of hemodialysis and renal homotransplantation upon coagulation.

\section{Methods}

Most of the uremic ratients studied had been admitted to the hospital for hemodialysis; many ultimately became candidates for renal homotransplantation. The studies obtained at admission were considered as controls against which to judge the 


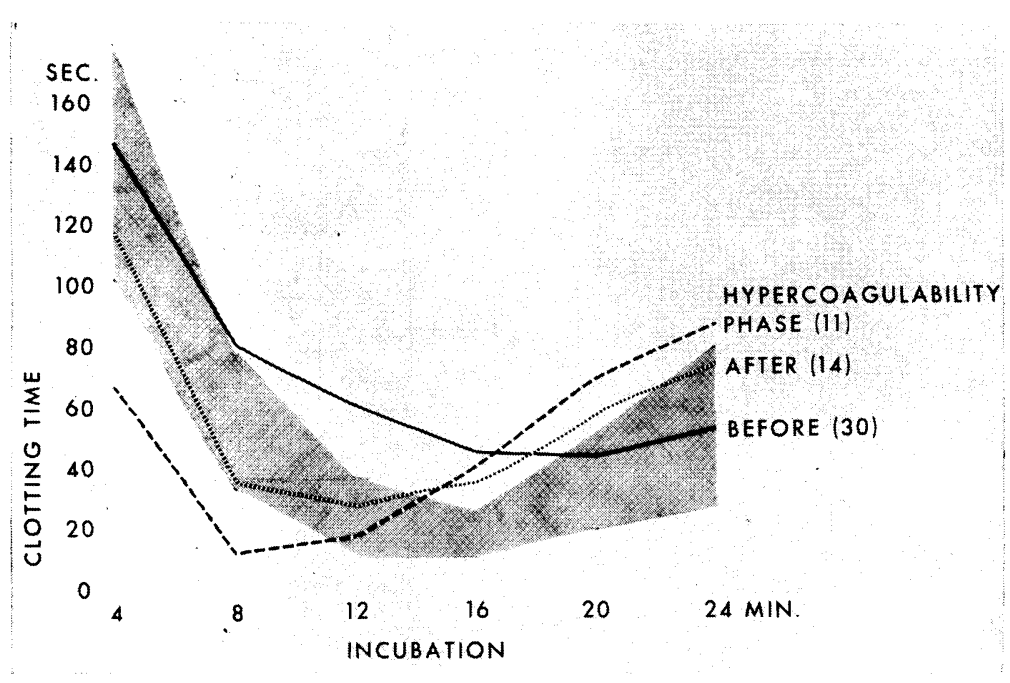

Fig 1.-Thrombin generation pattern in uremic patients before and after homotransplantation of kidney. (Shaded Area) Range of value from 25 healthy individuals. (Black Curve) Average thrombin generation values of 34 uremic patients indicating deficient thrombin generation. (Dotted Curve) Average thrombin generation values of 14 patients one to ten days after transplantation showing normalization. (Dashed Curve) Average thrombin generation values of 11 patients 10 to 75 days after transplantation of the kidney, indicating hypercoagulability. effect of subsequent therapy or of progression of disease. The following tests were performed: thrombin generation, ${ }^{16}$ recalcification time, and prothrombin consumption measured as serum prothrombin time, ${ }^{15}$ prothrombin complex measured as prothrombin time with the use of human brain thromboplastin, ${ }^{15}$ thrombelastograms, ${ }^{17}$ thrombin time $^{18}$ and euglobulin lysis time. ${ }^{13}$ Blood platelets were usually counted with the phase microscope, ${ }^{3}$ or, alternatively, estimated upon smear. Blood for all examinations was obtained with the two syringe technique using siliconized equipment and using citrate as anticoagulant (four parts blood to one part $3.8 \%$ sodium citrate). Centrifugation for separation of plasma was carried out in siliconized tubes at $1,470 \mathrm{~g}$ for five minutes; with this procedure all the platelets remained in the supernatant plasma.

The thrombin generation test ${ }^{16}$ reflects the conversion of prothrombin to thrombin, a reaction which depends upon the activity of intrinsic blood thromboplastin. Freshly drawn plasma is recalcified and incubated and an aliquot added every four minutes to a standard fibrinogen solution. The clotting time of the fibrinogen solution is thus a measure of the speed and completeness of thrombin formation and ultimately for the amount of active thrombin remaining in the serum; the serial determinations provide data for graphs (Fig 1, 2, 3) which depict plasma incubation time (abscissa) and fibrinogen clotting time (ordinate).

Plasma was used for substitution tests in two ways. First, blood was drawn from a healthy donor and centrifuged at $1,470 \mathrm{~g}$ for five minutes. All platelets remained in the supernatant; this "fresh plasma" was used within 30 minutes. Secondly, the above preparation was converted to "fresh frozen platelet-rich plasma" by first freezing (at $-20 \mathrm{C}$ ) and then thawing. It was found that about half the platelets were destroyed by freezing and then thawing, thereby releasing platelet clotting factors; such plasma was used both for in vitro testing and for administration to patients. In both kinds of plasma, the original number of platelets was greater than

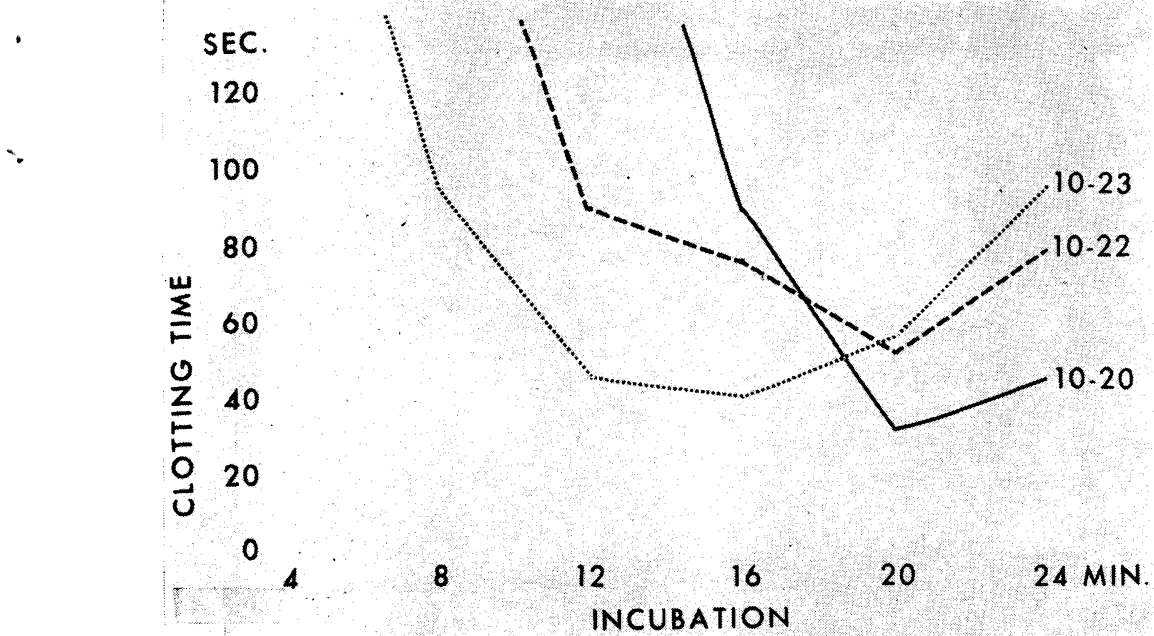

Arch Surg-Vol 92, Feb 1966
Fig 2.-Effect of hemodialysis upon thrombin generation in patient 9 (chronic glomerulonephritis). Oct 20: before dialysis. Activity of prothrombin complex $45 \%$, platelets 163,000, BUN $316 \mathrm{mg} / 100 \mathrm{cc}$. Oct 22 : after two dialyses. Platelets 91,250 ; BUN 262 $\mathrm{mg} / 100$ cc $10-23$ : BUN $160 \mathrm{mg} / 100 \mathrm{cc}$. Thrombin generation starts at normal time after third hemodialysis; yield, however, remains deficient. 


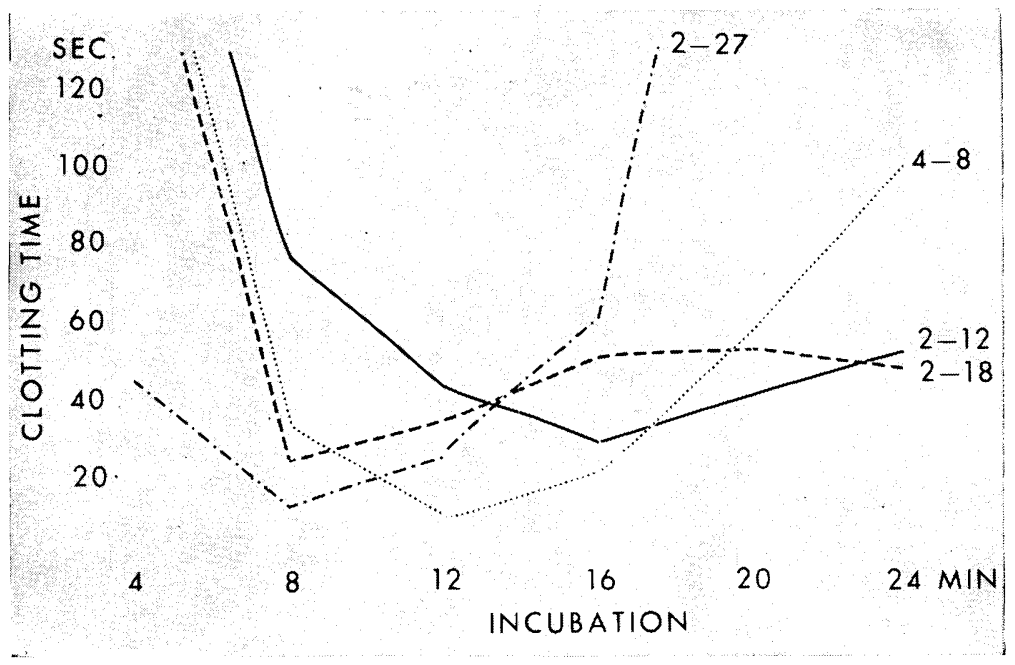

Fig 3.-Trend of thrombin generation pattern before and after homotransplantation of kidney (chronic glomerulonephritis). Patient 15. Curve, Feb 12: five days before transplantation. Platelets 244,000; BUN $174 \mathrm{mg} /$ 100 cc. Curve, Feb 18: one day after homotransplantation. Marked improvement. Platelets 285,000; BUN $43 \mathrm{mg} /$ 100 cc. Curve, Feb 27: hypercoagulability. Platelets 581,000; BUN 29 $\mathrm{mg} / 100$ cc. Curve, April 8: normal pattern. Platelets not done; BUN 22 $\mathrm{mg} / 100 \mathrm{cc}$.

in conventional blood bank preparations since the speed of centrifugation was less than that customarily used.

In vitro replacement therapy was also carried out with the human brain lipid prepared according to Bell and Alton, ${ }^{2}$ using a 1:100 dilution with buffered saline at $\mathrm{pH}$ 7.4. Serum prothrombin times were measured before and after the addition of the brain lipid.

\section{Results}

Untreated Uremic Patients.-Studies performed shortly after admission revealed various clotting defects. Thrombin generation after 12 and 16 minutes incubation was abnormal in $82 \%$, or 30 of 34 patients (Fig $1)$. In 22 of 26 cases $(85 \%)$, the thrombin time was prolonged. Serum prothrombin time was short (below 30 seconds) in 14 of $24(58 \%)$. In 16 of 33 patients, the number of platelets was reduced to one half to two thirds normal. The prothrombin complex (Quick one-stage prothrombin time) was reduced in 15 of 15 patients to an average of $40 \%$ (range $17 \%$ to $64 \%$ ). None of 41 patients tested had reduced euglobulin lysis times; on the contrary, the values tended to be longer than normal.

With progression of uremia, further deterioration of all the above clotting parameters was observed. Serial thrombelastograms showed a progressive delay in the beginning and progression of the clot formation. Most severely affected were thrombin generation and the prothrombin complex. Thrombocytopenia of one fourth or less the normal value was seen. Even in such terminal patients, there was no increase in fibrinolytic activity.

In Vitro Correction of the Clotting $A b$ normalities.-Since deficient thrombin generation, abnormal prothrombin consumption (shortened serum prothrombin time), or both were the most common and most serious clotting defects, attempts were made to restore normal coagulation in the test tube by the addition of reagents. In this way, infor-

Table 1.-Serum Prothrombin Time (Seconds) in Uremic Plasma Before and After Addition of Fresh Plasma, Fresh-Frozen Plasma, or Brain Lipid (Normal Values: Above 35 Seconds)

\begin{tabular}{|c|c|c|c|c|c|c|}
\hline Patient & Diagnosis & $\begin{array}{l}\text { Without } \\
\text { Addition }\end{array}$ & $\begin{array}{c}\text { Plus } 10 \% \\
\text { Fresh Plasma }\end{array}$ & $\begin{array}{c}\text { Plus 5\% } \\
\text { Fresh-Frozen Plasma }\end{array}$ & $\begin{array}{c}\text { Plus 5\% } \\
\text { Brain Lipid }\end{array}$ & Platelets \\
\hline 1 & Polycystic kidney & 25.7 & 28.7 & 67.8 & 43.7 & 179,000 \\
\hline 2 & Acute anuria (postsurgical) & 26.8 & $32.3^{*}$ & 61.9 & 94.5 & 125,000 \\
\hline 3 & Chronic glomerulonephritis & 22.6 & 50.6 & 61.5 & 145.0 & 127,000 \\
\hline 4 & Chronic bilateral pyelonephritis & 29.6 & $28.8^{*}$ & 86.3 & 168.6 & 162,000 \\
\hline 5 & Chronic glomerulonephritis & 20.7 & 31.1 & 59.7 & 91.4 & 92,000 \\
\hline 6 & Chronic glomerulonephritis & 22.2 & $28.2^{*}$ & 49.7 & 56.5 & 300,000 \\
\hline 7 & Chronic glomerulonephritis & 29.2 & 58.5 & 108.0 & 52.0 & 112,000 \\
\hline
\end{tabular}

* Only partial correction on addition of $50 \%$ fresh plasma. 
Table 2.-Serum Prothrombin Time, Thrombin Time, and Thrombin Generation Before and After Hemodialysis*

\begin{tabular}{|c|c|c|c|c|c|c|c|}
\hline \multirow[b]{2}{*}{ Patient } & \multirow[b]{2}{*}{ Diagnosis } & \multicolumn{3}{|c|}{ Serum Prothrombin Time } & \multicolumn{2}{|c|}{ Thrombin Time } & \multirow{2}{*}{$\begin{array}{c}\text { Thrombin Generation } \\
\text { After Dialysis }\end{array}$} \\
\hline & & Before & (...) Days & After & Before & After & \\
\hline 3 & Chronic glomerulonephritis & 22.6 & 1 & 25.0 & 33.6 & 30.7 & Improved \\
\hline 8 & Chronic glomerulonephritis & 26.3 & 1 & 44.0 & 25.2 & 23.2 & Not improved \\
\hline 9 & Chronic glomerulonephritis & 35.2 & 1 & 44.2 & 33.0 & 25.0 & Improved \\
\hline 6 & Chronic glomerulonephritis & 22.3 & 1 & 48.0 & 28.0 & 23.0 & Improved \\
\hline 1 & Polycystic kidney & 29.1 & 4 & 29.8 & 18.8 & 16.8 & Slightly improved \\
\hline 10 & Chronic pyelonephritis & 19.8 & 5 & 44.6 & 17.3 & 17.0 & Not done \\
\hline
\end{tabular}

* Thrombin generation tests were carried out in the blood samples drawn for serum prothrombin time.

mation was sought which could be applied for the planning of corrective systemic therapy.

The deficient prothrombin consumption was restored by the addition of brain lipid (Table 1) both in the samples containing normal platelets or in those with mild thrombocytopenia. Since brain lipid has similar clotting properties to those of platelet factor-3, this finding was compatible with the hypothesis that the deficient prothrombin consumption was due to platelet dysfunction and led to further studies with replacement of platelet factors. First, fresh plasma was added to the patient's uremic plasma. Although improvement in prothrombin consumption occurred in some cases, there was no correction by fresh plasma in others (Table 1) at the standard $10 \%$ aliquot and sometimes even when up to $50 \%$ was added. The latter observation suggests that uremic plasma may exert an inhibitory influence on the prothrombin consumption of normal plasma.

In contrast, the addition of $5 \%$ freshfrozen platelet-rich plasma obtained from the same donor restored prothrombin consumption in every case (Table 1). These findings support the possibility that the platelets, which are destroyed by freezing and thawing, release platelet factor-3 (or some other involved component) which in turn binds some substance in uremic plasma which inhibits thrombocyte function.

In Vivo Correction of the Clotting Abnormalities.-In several patients, a clinically obvious bleeding diathesis seemed to be improved with infusion of $750 \mathrm{ml}$ fresh-frozen platelet-rich plasma. In one patient with diffuse mucosal hemorrhage $750 \mathrm{ml}$ freshfrozen platelet-rich plasma was given concomitantly with a fractionated intravenous dose of $50 \mathrm{mg}$ phytonadine. The bleeding stopped abruptly. Prothrombin complex rose from $7 \%$ to $45 \%$ and there was improvement of the thrombelastogram and thrombin generation for the ensuing two weeks.

Effect of Hemodialysis on Clotting Abnormalities.-Six patients were studied. Five had poor prothrombin consumption and reduced thrombin generation; the sixth had deficient thrombin generation alone. After hemodialysis, all six patients had some improvement of prothrombin consumption, as indicated by subsequent prolongation of the serum prothrombin time (Table 2). Thrombin generation was also improved (Fig 2) in four of the five cases in which it was determined (Table 2). In all cases there was

TABLE 3.-Serum Prothrombin Time Before and After Homotransplantation of the Kidney (Normal Values: Above 35 Seconds)

\begin{tabular}{|c|c|c|c|c|c|c|}
\hline \multirow[b]{2}{*}{ Patient } & \multirow[b]{2}{*}{ Diagnosis } & \multicolumn{3}{|c|}{ Serum Prothrombin Time } & \multirow[b]{2}{*}{ Platelets Before } & \multirow[b]{2}{*}{ Platelets After } \\
\hline & & Before & (...) Days & After & & \\
\hline 11 & Chronic glomerulonephritis & 24.7 & 3 & 67.0 & Average & 201,000 \\
\hline 12 & Chronic glomerulonephritis & 19.0 & 17 & 69.0 & 100,000 & 209,000 \\
\hline 13 & Chronic glomerulonephritis & 27.4 & 60 & 71.8 & 217,000 & 466,000 \\
\hline 14 & Chronic glomerulonephritis & 20.2 & 130 & 77.4 & 163,000 & average \\
\hline
\end{tabular}

Arch Surg-Vol 92, Feb 1966 
TABlE 4.-Thrombin Time (Seconds) Before and After Homotransplantation of The Kidney (Normal Range: 14-16 Seconds)

\begin{tabular}{cccc} 
& & \multicolumn{2}{c}{ After Transplantation } \\
\cline { 3 - 4 } Patient & Before & 1-5 Days & 1 Month \\
15 & 37.0 & 17.6 & 17.7 \\
16 & 20.5 & 16.0 & 18.4 \\
17 & 28.4 & 21.5 & 15.4 \\
18 & 22.4 & 18.4 & 16.0 \\
12 & 30.0 & 17.1 & 16.0 \\
19 & 25.0 & 18.0 & 14.1 \\
Average & 27.2 & -18.1 & 16.3
\end{tabular}

some shortening of the thrombin time (Table 2) after hemodialysis.

The Influence of Homotransplantation.Clot formation improved in each of 14 patients who received a well-functioning renal homograft. Serum prothrombin times rapidly returned to normal (Table 3 ). In six of six patients the thrombin times were shortened and eventually normalized (Table 4). Serial thrombelastograms showed marked improvement of the timing and development of the clot, often within a day or two (Fig 4). Thrombin generation was equally improved in each of 14 patients (Fig 1). The correction was essentially complete by the first to tenth posttransplant day. Moreover, the acute increase in thrombin generation actually exceeded the normal pattern in most instances inasmuch as it started too early, provided a premature maximum yield, or both (Fig 1); the resultant hypercoagulability was in general greatest from 10 to 17 days after operation.

The effects of restoration of renal func- tion are even more evident in the study of individual cases such as that depicted in Fig 4 and 5 . In these patients the typical deficiency of thrombin generation existed before operation. Within one to three days after transplantation, this was dramatically restored toward normal; there had been essentially no change in the platelet count. In the patient shown in Fig 4, there was slight hypercoagulability after nine days of good homograft function, but by the seventh postoperative week, the pattern was normal.

In those patients who achieved long-term survival, the correction of the clotting abnormalities was parallel to the quality of homograft function. However, when rejection occurred, the coagulation defects reverted to the typical uremic pattern.

All patients who received a successful homotransplantation had a marked rise of antithrombin III activity. ${ }^{19}$ In no case has this returned to normal, even after observation for more than two years. The details

\footnotetext{
Fig 4.-Thrombelastograms before and after homotransplantation of kidney (chronic glomerulonephritis. (Patient 20: thrombelastogram on Oct
14 , four days before transplantation, platelets 62,000 , BUN $148 \mathrm{mg} /$ 100 cc. Thrombelastogram on Oct 21 , three days after transplantadays after transplanta-
tion, platelets 95,000 , BUN $20 \mathrm{mg} / 100 \mathrm{cc}$. This thrombelastogram is normal. Center strip of the presurgical thrombelastogram indicating severe platelet insufficiency has disappeared and fibrin formation starts at normal time.
}

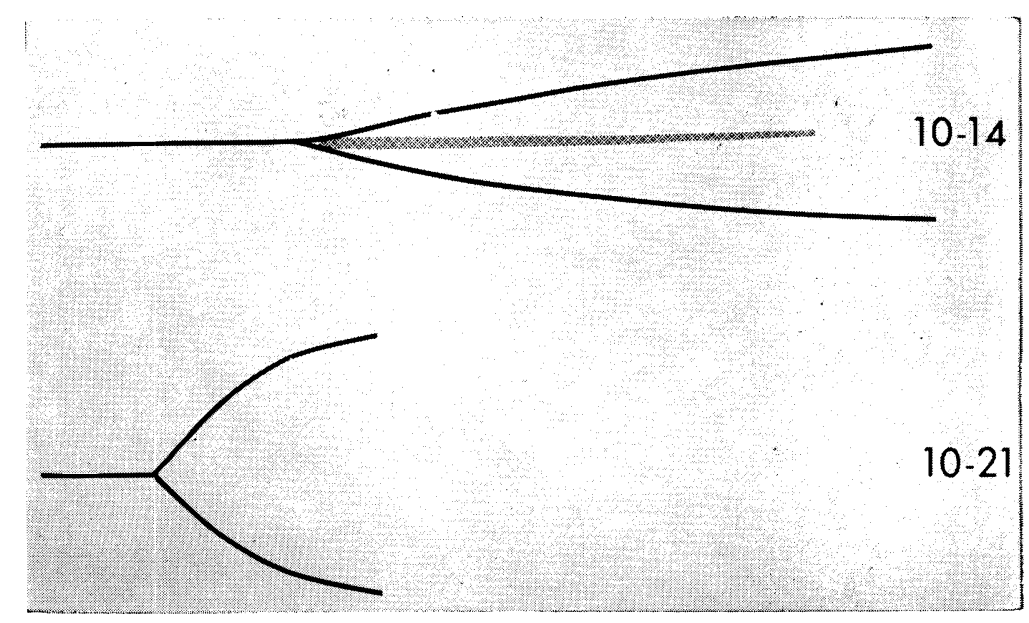

Arch Surg-Vol 92, Feb 1966 
and possible significance of this observation will be reported separately.

\section{Comment}

The foregoing data suggest that the specific coagulation deficiencies in uremia are essentially due to platelet disorders; the abnormal serum prothrombin times and the retarded thrombin generation are explicable on this basis since in vitro correction is possible by addition of material with platelet factor-3 function. The poor clotting is apparently not due primarily to a reduction in the number of platelets, since significant thrombocytopenia was a relatively uncommon finding except in terminal cases. Furthermore, in vitro correction was accomplished less effectively with fresh plasma with its normal platelet count than with fresh-frozen plasma or brain lipid which either contained a reduced number of platelets or none at all, respectively.

Instead, the findings in the present study support the contention of Cahalone et $\mathrm{al}^{4}$ who believed that some substance was present in uremic plasma which inhibited platelet function; they demonstrated that such plasma abolished the coagulating function of normal platelets within 18 hours. Inasmuch as the clotting abnormality may be improved by hemodialysis it might be contended that the hypothetical material can cross the membrane of the artificial kidney, although such an interpretation is highly speculative since the homologous blood used to prime the extracorporeal circuit may theoretically have contributed. The beneficial effect of agents such as fresh-frozen platelet-rich plasma and brain lipid raise the possibility that platelet factor-3 may bind with and inactivate the inhibitory factor.

Other changes in coagulation were minor and probably relatively nonspecific. Prolonged thrombin times similar to those in the present report have been seen in patients with heart disease $\mathbf{1 5 , 2 0}$ and other chronic illnesses. The moderate reduction in prothrombin complex (factors II, V, VII, X) reported in the present study is probably clue at least in part to the liver disease which often accompanies uremia. ${ }^{8}$ That the hepatic injury was not severe is indicated by the facts that plasma fibrinogen tended to be higher than normal and that there was no increased fibrinolytic activity.

The retarded thrombin generation could be easily restored to normal in the test tube, but the effects of systemic therapy or renal hemodialysis were far less predictable. Although examples of apparent improvement of this test were seen both with infusion of fresh-frozen platelet-rich plasma (in combination with phytonadine), or with hemodialysis, the correction was at best partial and transient. In contrast, successful homotransplantation restored effective coagulation rapidly, for as long as adequate renal function was maintained, and without fail. An

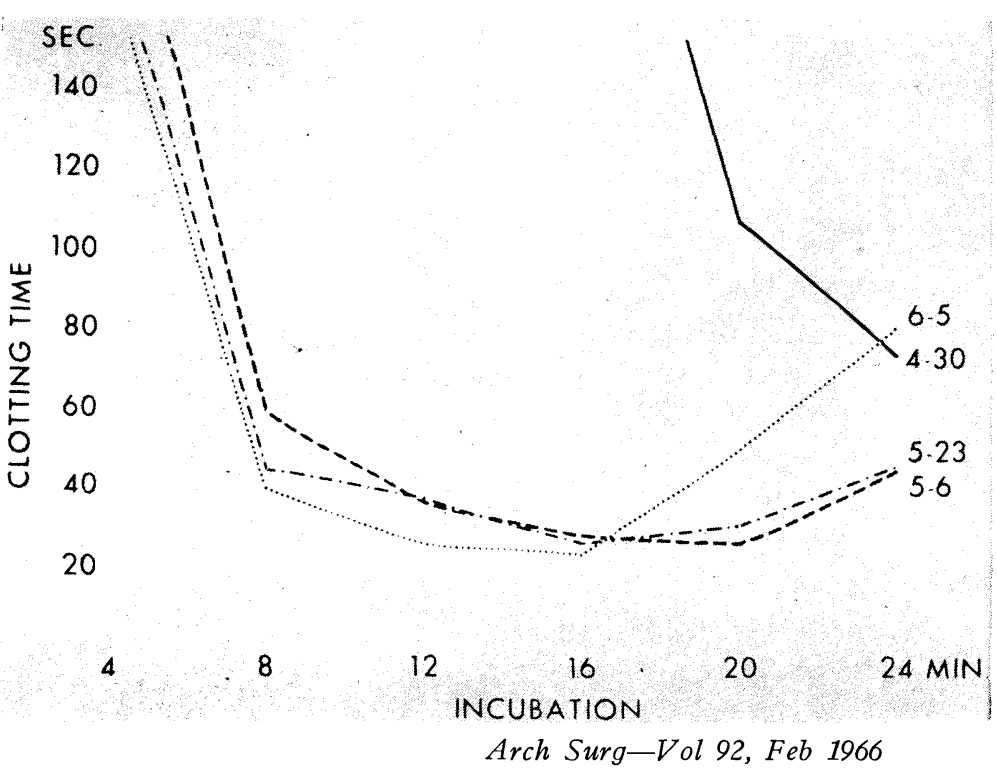

Fig 5.-Trend of thrombin generation pattern before and after homotransplantation of kidney (chronic glomerulonephritis). Patient 11 Curve, April 30: very deficient thrombin generation. Adequate platelets on smear; BUN $230 \mathrm{mg}$ / 100 cc. Curve, May 6: three days after transplantation. Marked improvement. Platelets 201,000; BUN $25 \mathrm{mg} /$ 100 cc Curve, May 23: no change. Platelets 569,000 ; BUN $37 \mathrm{mg} / 100 \mathrm{cc}$ Curve, June 5: further improvement but not completely normal thrombin generation. Platelets 553,000; BUN 46 mg/100 cc. 
improvement, if not a complete correction, was often present within 24 hours. Conceivably, some of the immediate alterations could have been attributable to the nonspecific effects of surgery, to blood transfusions used at this time, to the splenectomy which was also performed in all of these patients, ${ }^{11}$ or to the administration of corticosteroids in many cases. Nevertheless, the principal benefit was clearly the consequence of reestablishment of adequate renal excretion. It deteriorated only with the return of renal failure. Control studies performed prior to transplantation indicated that azathioprine was without influence on the results of the coagulation studies.

In actuality, the intensity of clotting not only reached, but exceeded, normal values during the first few weeks, rendering the patients hypercoagulable from a laboratory point of view. Whether the degree of hypercoagulability is unique in renal homotransplantation, is the consequence of immunosuppressive drugs other than azathioprine, splenectomy, or both, or is only an exaggeration of the well-known increased tendency to accelerated clotting after any operation cannot be answered with certainty. It is, however, worth noting that the incidence of pulmonary embolization in cases of homotransplantation has been materially greater than in the average postoperative patient. ${ }^{11}$

In the course of this study, a battery of examinations was carried out not only in order to characterize the abnormalities of clotting which might be present, but also to define which tests would have the greatest practicality for the study and management of future cases. In view of the findings herein reported, it is thought that the ideal analysis should be sensitive for platelet function and endogenous inhibitors, should measure both hypercoagulability and hypocoagulability, and should be suitable for visual inspection in graphs or curves so that the changing kinetics of coagulation can be followed during the course of the disease and its therapy. Although the thrombin generation test and the thrombelastogram measure both overlapping but different clotting parameters, both examinations partially ful- fill all three criteria. Since the thrombin time measures both heparin and heparin-like thrombin inhibitors, it adds a potentially useful additional dimension. None of the three examinations requires plasma dilution, so that the natural relation between factors inhibiting and promoting coagulation is not disrupted. Other tests can be considered as ancillary and used for the answer of specific detailed questions.

\section{Summary}

Blood coagulation was studied in patients with chronic renal failure in order to characterize the clotting deficiency in such patients and to assess the effects of therapy. The most common abnormalities of uremia seemed attributable to platelet dysfunction with consequent reduction of the conversion of prothrombin to thrombin; reduced thrombin generation and shortened serum prothrombin times resulted. This defect was apparently not usually caused by thrombocytopenia. Rather, it appeared that some substance may have been present in azotemic plasma which inhibited platelet function. In vitro addition of substances such as brain lipid or fresh-frozen platelet-rich plasma corrected the coagulation deficiency. Systemic therapy with fresh-frozen plateletrich plasma seemed of some benefit.

Hemodialysis was shown to improve clotting in several cases but this effect was inconstant and transient. In contrast, renal homotransplantation rapidly restored good coagulation in direct parallel with and for as long as the persistence of good renal function. The correction usually exceeded normal, leading to a state of hypercoagulability primarily from the first to third postoperative weeks; this transient finding could help explain the heightened incidence of pulmonary embolization during this time.

This study was supported by grant $\mathrm{HE} 5538$ and 5 T1 5638 from the National Heart Institute, US Public Health 5638 from the National Heart Institute, US Public Health
Service; and AM 06283, AM 06344, HE 07735, AM 07772, AI 04152, FR 00051, and FR 00069 from the US Public Health Service.

\section{REFERENCES}

1. Altschueler, G.; Marcus, J.; and Ullman, H.L.: Platelets and Platelet Phosphatides in Uremia, Blood 16:1439, 1960.

2. Bell, W.N., and Alton, H.G.: A Brain Ex- 
tract as a Substitute for Platelet Suspension in the Thromboplastin Generation Test, Nature $174: 880$, 1954.

3. Brecher, C.; Schneiderman, M.; and Cronkite, E.P.: The Reproducibility and Constancy of Platelet Count, Amer J Clin Path 33:15, 1953.

4. Cahalone, S.F., et al: Acquired Thrombopathia, Amer J Clin Path 30:507, 1958.

5. Castellanos, H.: Alteracions en la hemostasia en la uremia cronica, Pren Med Argent $51: 24$, 1964.

6. Cheney, K., and Bonnin, J.A.: Coagulation Defect in Uremia, Brit J Haemat 8:215, 1962.

7. Geiger, M.T.; Sander, J.M.; and Rath, C.E. : Evidence for a Qualitative Platelet Defect in Uremia, abstracted, Blood $15: 428,1960$.

8. Gross, R.; Nieth, H.; and Mammen, E. : Blutungsbereitschaft und Gerinnungsstoerungen bei Uraemie, Klin Wschr 36:107, 1958.

9. Kendall, A.G.; Lowenstein, L.; and Morgan, R.O.: The Hemorrhagic Diathesis in Renal Disease, Canad Med Assoc J $85: 405,1961$.

10. Lewis, J.H.; Zucker, M.B.; and Ferguson, J.H.: Bleeding Tendency in Uremia, Blood 11: 1073, 1956.

11. Starzl, T.E.: Experience in Renal Transplantation, Philadelphia: W. B. Saunders Co., 1964.

12. von Kaulla, K.N.: Zur klinischen Bedeutung und Technik des Heparintoleranztestes in vitro, Deutsch Med Wschr 78:1075, 1953.

13. von Kaulla, K.N., and Schultz, R.L.: Methods for Evaluation of Human Fibrinolysis: Studies With Two Combined Techniques, Amer $J$ Clin Path $29: 104,1958$.

14. von Kaulla, K.N., and Swan, H.: Clotting Deviations in Man Associated With Open-Heart
Surgery in Hypothermia, $J$ Thorac Surg $36: 857$, 1958.

15. von Kaulla, K.N.; Swan, H.; and Paton, B.: Variations of the Thrombin Time in Certain $\mathrm{Pa}$ tients Undergoing Open-Heart Surgery: Discussion of Its Prognostic Significance, J Thorac Cardiov Surg 40:260, 1960.

16. von Kaulla, K.N., and von Kaulla, E.: Thrombin Generation in Normal Subjects and in Cardiac Patients, Circ Res $14: 436,1964$.

17. von Kaulla, K.N., and von Kaulla, E.: "Thrombelastography: A Method of Continuous Recording of Fibrin Formation and Fibrinolysis," in Tocantins, L.M., and Kazal, L.A., eds.: Blood Coagulation, Hemorrhage, and Thrombosis, New York: Grune \& Stratton, 1964, pp 34-40.

18. von Kaulla, K.N., and von Kaulla, E.: "Estimation of the Thrombin Time of Plasma," in Tocantins, L.M., and Kazal, L.A., eds.: Blood Coagulation, Hemorrhage and Thrombosis, New York: Grune \& Stratton, 1964, pp 335-340.

19. von Kaulla, K.N., and von Kaulla, E.: Thrombin Generation and Antithrombin III Activity in Homotransplantation of the Human Kidney; Tenth Congress of the International Society of Hematology, Stockholm, 1964, Abstract G-35.

20. von Kaulla, K.N., and von Kaulla, E.: Observations With the Thrombin Time of Plasma in Health and Disease, to be published.

21. Rath, E.; Maillard, J.A.; and Schreiner, G.E.: Bleeding Tendency in Uremia, New Eng $J$ Med $257: 808,1957$.

22. Wurzel, H.A.: "The Coagulation Defects in Uremia," in Proceedings of the VI International Congress, International Society of Hematology (Rome, 1958) New York: Grune \& Stratton, 1960, vol 2, 1187-1190. 


\title{
Histologic Changes in Clinically Normal Breasts at Postmortem Examination
}

\author{
LOREN J. HUMPHREY, MD, BUFFALO, NY, AND MARTIN SWERDLOW, MD, CHICAGO
}

IN A PREVIOUS publication ${ }^{1}$ we reported that severe epithelial hyperplasia of the large ducts was found in $69 \%$ of breasts removed for carcinoma and in only $16 \%$ of breast tissue diagnosed as "fibrocystic disease." Having defined and used our own criteria for the micropathological characterization of benign breast changes associated with carcinoma of the breast and "fibrocystic disease" of the breast, it became necessary to ascertain the frequency of these changes in clinically normal breasts.

This study was undertaken to determine the breast changes in 100 consecutive autopsies of women 20 years of age and older with clinically normal breasts.

\section{Methods and Results}

This histologic study, as our previous study, evaluated severe epithelial hyperplasia of the large ducts, the small ducts, and the acini. The presence or absence of fibrosis, sclerosing adenosis, papillomas, apocrine changes, and cysts was noted. The detailed criteria for microscopic changes was described in a previous publication. ${ }^{3}$

Beginning with Jan 1, 1955, we reviewed the autopsy records of the pathology department of University of Illinois Research and Educational Hospital, Chicago. Reports of 100 consecutive postmortem examina-

Submitted for publication Nov 1, 1965.

From the departments of pathology and surgery, University of Illinois College of Medicine, Chicago.

Reprint requests to 462 Grider St, Buffalo, NY 14215 (Dr. Humphrey). tions in women 20 years of age and older with clinically normal breasts were reviewed. Slides of breast tissue from these autopsies were evaluated. It can be seen from the Table that in only $6 \%$ of these cases could we find severe epithelial hyperplasia of the large ducts. Severe epithelial hyperplasia of the small ducts and epithelial hyperplasia of acini was found in $17 \%$ and $21 \%$, respectively. For comparison with the benign breast changes associated with fibrocystic disease and carcinoma of the breast see columns 2 and 3 of the Table. The results of our studies of benign breast changes associated with fibrocystic disease and carcinoma of the breast were published previously ${ }^{1}$ and are included for illustrative purposes.

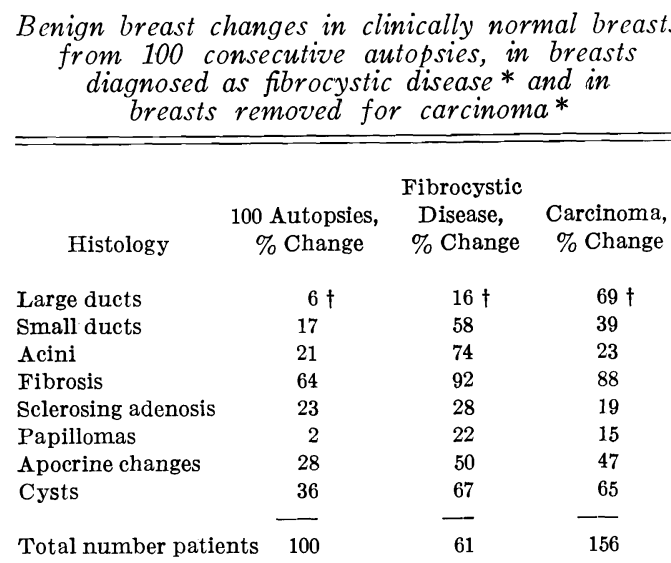

${ }^{*}$ Columns 2 and 3 which were previously reported ${ }^{1}$ are included for comparison with results in column 1 .

$\dagger$ Figures represent percent of patients in each group with histologic changes. 